\title{
Erratum to: The estimated incidence of pertussis in people aged 50 years old or older in the United States, 2006-2010
}

Cristina Masseria ${ }^{{ }^{*}}$ and Girishanthy Krishnarajah ${ }^{2^{*}}$

\section{Erratum}

After publication of the original article [1], it came to the authors' attention that the title had been incorrectly published as The estimated incidence of pertussis in people aged 50 years old in the United States, 2006-2010.

"50 years old" should have read as "50 years or older", so the title should have read: The estimated incidence of pertussis in people aged 50 years old or older in the United States, 2006-2010. The correct title of the original article appears in this erratum.

Published online: 25 April 2016

\section{References}

1. Masseria, C and Krishnarajah, G. The estimated incidence of pertussis in people aged 50 years old or older in the United States, 2006-2010. BMC Infect Dis. 2015;15:534. doi:10.1186/s12879-015-1269-1.

* Correspondence: cristina.masseria@pfizer.com;

'Global Health \& Value, Pfizer Inc., 235 E 42nd street, New York, NY 10017 USA

${ }^{2}$ Vaccines, GlaxoSmithKline Vaccines, 5 Crescent Dr, Philadelphia, PA 19112,

USA 